\title{
EDUCAÇÃO E CIDADANIA: REFLEXÕES SOBRE UM DEBATE CONTEMPORÂNEO
}

\section{Luís Fernando Santos Corrêa da Silva ${ }^{1}$ \\ Thiago Ingrassia Pereira ${ }^{2}$}

\begin{abstract}
Resumo: Este artigo trata do panorama do direito à educação no Brasil contemporâneo, mobilizando conceitos da teoria social para discutir as interconexões entre cidadania e educação, bem como as contribuições de estudiosos brasileiros do tema. Inicialmente, cabe destacar que a experiência histórica do Brasil, em relação aos direitos sociais, difere substancialmente do que ocorreu nos países do centro capitalista, pois estes últimos viveram a experiência do Welfare State. Por outro lado, em termos conceituais, os direitos precisam ser compreendidos como historicamente relativos, visto que o que é legitimado socialmente como relevante em uma sociedade específica, ou em uma determinada época histórica, pode ser desconsiderado em outras. Considerando o percurso histórico do Brasil no século XX, é possível identificar avanços e retrocessos no acesso à cidadania, com efeitos significativos para a educação. No Brasil contemporâneo, a construção da cidadania, por meio do acesso à educação, tem suscitado questões que remetem à relação entre acesso, qualidade, e legitimação do direito à educação, visto que é no bojo do processo educativo que ocorre um importante movimento recíproco: acesso e qualidade da educação são aspectos condicionados pelo reconhecimento da legitimidade do direito à educação, do mesmo modo que a construção da legitimidade do direito à educação é dependente da capacidade das sociedades em garantir acesso e qualidade nos processos formativos. Desse modo, tornam-se indissociáveis o direito à educação, a legitimação desse direito e a cidadania, inseridos no movimento de ampliação dos horizontes do entendimento humano sobre o mundo.
\end{abstract}

Palavras-chave: Educação para a cidadania. Direitos sociais. Educação no Brasil.

1 Doutor em Sociologia (UFRGS). Professor do Programa de Pós-Graduação Interdisciplinar em Ciências Humanas da Universidade Federal da Fronteira Sul (UFFS).

2 Doutor em Educação (UFRGS). Professor do Programa de Pós-Graduação Interdisciplinar em Ciências Humanas e do Programa de Pós-Graduação Profissional em Educação, ambos da Universidade Federal da Fronteira Sul (UFFS). 


\section{INTRODUÇÃO}

A noção de cidadania remete à aquisição de prerrogativas relacionadas ao pertencimento a uma sociedade e, na modernidade, está intrinsecamente relacionada aos direitos considerados relevantes em contextos sociais específicos ou em escala global. Tais direitos são representados por uma relativa variedade de garantias, que remetem aos seguintes âmbitos: a) vida civil do indivíduo, como o direito à liberdade, de ter a sua integridade física preservada e de dispor do próprio corpo; b) participação política, como o direito de votar e ser votado e de participar de organizações promotoras de ação coletiva, como partidos políticos, movimentos sociais, associações e sindicatos de classe; c) bem-estar social, como o direito à moradia, à saúde, à educação e à proteção social. $\mathrm{O}$ acesso a essas classes de direitos não é fixo, pois permite avanços e retrocessos ao longo do tempo, tampouco há uma correlação necessária entre tipos diferentes de direitos, visto que são possíveis diversos arranjos entre eles, o que muitas vezes nos permite encontrar sociedades em que o peso de cada classe de direitos encontra-se representado em maior ou menor grau.

Neste cenário, o direito à educação, como direito social, surge como elemento capaz de promover mudanças radicais nas sociedades modernas, porque a prática educativa permite qualificar a relação que a humanidade estabelece com a natureza, e também porque possui potencial problematizador inegável, mediante as possibilidades de desnaturalização da realidade que engendra. Na modernidade, a importância da educação vem se impondo valorativamente em um quadro de tensões entre concepções educacionais distintas, seguindo orientação tecnicista ou humanizadora. Ademais, as possibilidades e os usos da educação encontram finalidades diversas, contribuindo para o desenvolvimento material e simbólico das sociedades.

Neste artigo, sem a pretensão de esgotar o debate sobre o tema, procura-se refletir sobre o panorama do direito à educação no Brasil contemporâneo, mobilizando, para tanto, a teoria social que discute as interconexões entre cidadania e educação, bem como as contribuições de estudiosos brasileiros que têm se debruçado sobre a temática. Diferentemente do que ocorreu nos países do centro capitalista, o Brasil não viveu experiência similar ao Welfare State, e apenas recentemente conseguiu universalizar o acesso ao ensino fundamental. Mesmo que a educação seja valorizada nos discursos governamentais e entendida pela população como elemento decisivo para a mobilidade social ascendente, no Brasil, o seu papel no desenvolvimento econômico e social ainda carece de maior legitimidade. 


\section{CIDADANIA E TEORIA SOCIAL}

A discussão sobre cidadania tem sido objeto de reflexão sociológica desde a constituição da disciplina, mediante a análise das características gerais que distinguem a nossa época em termos da aquisição de direitos, mas também considerando as especificidades históricas dos contextos locais, em termos de suas formas de organização, cultura, relação entre Estado, mercado e sociedade civil, valores partilhados, entre outros aspectos. Não menos importante é o papel da educação como um direito social, sempre relevante quando se trata do cenário moderno de ampliação da cidadania.

Autores como Bauman (2001) e Cerquier-Manzini (2010) sustentam que a valorização do trabalho representa um marco distintivo para a efetivação da cidadania em sua forma moderna. Se na antiguidade clássica o trabalho era visto como algo indigno, destinado apenas aos escravos e definido como condição não humana, e na idade média o trabalho esteve permeado por relações de servidão, em uma rígida hierarquia social, na modernidade, a contribuição de cada um e de todos por meio da participação na divisão social do trabalho passou a ser compreendida como elemento unificador de um projeto de civilização, dotado de legitimidade social crescente.

Na modernidade, a ascensão da burguesia como classe social hegemônica condiciona a construção de uma nova diretriz ideológica sobre a forma de viver, pautada em uma visão de mundo que legitima a propriedade privada como direito humano natural. Neste contexto, a educação possui um papel decisivo, visto que cabe a ela garantir a incorporação dos valores burgueses por indivíduos e grupos sociais específicos (CERQUIER-MANZANI, 2010).

Contudo, a noção de direito natural não é uma novidade histórica, tampouco foi cunhada na modernidade. A noção de direito natural (jusnaturalismo) surgiu na Grécia antiga, sustentada no argumento de que há bens humanos evidentes, que seriam perceptíveis mediante o julgamento da razão prática e por critérios de razoabilidade. Esse entendimento se baseia na tese de que a condição humana, per se, é fundamento que confere legitimidade a determinados direitos e permite sustentar, inclusive, o reconhecimento generalizado de sua relevância (BOBBIO, 2004).

Em contraposição ao argumento jusnaturalista, na contemporaneidade concebe-se que os direitos são historicamente relativos, pois o que é legitimado socialmente em uma época, ou por uma sociedade específica, pode ser desconsiderado em outra época, ou por outra coletividade, inserida em um contexto cultural distinto. Como classe variável que compõe o principal suporte 
da noção moderna de cidadania, os diretos estão permanentemente em disputa, visto que, inclusive, a afirmação de um novo direito pode acarretar na negação de um direito já estabelecido. No Brasil, por exemplo, até o final do século XIX, a posse de escravos era legitimada como um direito dos cidadãos livres, de modo que a abolição da escravidão representou, por um lado, a negação do direito a esse tipo de propriedade, e, por outro, o acesso aos direitos de cidadania (limitados) a indivíduos até então escravizados (BOBBIO, 2004).

Dentre as formas de acesso à cidadania, os direitos sociais se constituem na experiência mais recente do ponto de vista histórico. Enquanto o surgimento dos direitos políticos e civis remonta ao período da antiguidade clássica, os direitos sociais são uma forma contemporânea de direitos, vinculados ao processo de desenvolvimento capitalista. As pressões sociais e a luta política por melhores condições de vida, relacionadas ao trabalho, mas também a outras esferas, impuseram a afirmação de novos direitos. Sobre a ampliação de direitos, Bobbio sustenta que:

Essa multiplicação (ia dizendo "proliferação") ocorreu de três modos: a) porque aumentou a quantidade de bens considerados merecedores de tutela; b) porque foi estendida a titularidade de alguns direitos típicos a sujeitos diversos do homem; c) porque o próprio homem não é mais considerado como ente genérico, ou homem em abstrato, mas é visto na especificidade ou na concreticidade de suas diversas maneiras de ser em sociedade, como criança, velho, doente, etc. Em substância: mais bens, mais sujeitos, mais status do indivíduo. (BOBBIO, 2004, p. 63)

Esse conjunto de novas circunstâncias remete a um quadro de especificação dos direitos e de responsabilização do Estado por sua consecução, visto que, nas sociedades modernas, a existência de um direito depende de sistema normativo específico, e também, em muitos casos, de financiamento público. No caso da educação não é diferente: o direito à educação tornou-se responsabilidade do Estado e direito coletivo que precisa ser garantido a cada indivíduo, mediante o acesso a instituições de ensino regular, mesmo que na prática esse acesso seja condicionado por fatores estruturais (vide o vestibular, como forma de seleção e classificação para o acesso ao ensino superior) ou de ordem pessoal, relacionados às escolhas dos indivíduos.

Nas sociedades contemporâneas, o acesso aos direitos sociais, como a educação, tem ocorrido no contexto de profundas mudanças na estrutura social e na própria sociabilidade. Perspectivas teóricas críticas têm ressaltado o papel profundamente contraditório dos direitos surgidos da relação dos indivíduos 
com os mercados de consumo. Neste sentido, a noção de cidadania estaria intrinsecamente relacionada à condição de consumidor de produtos e serviços, encontrando respaldo, inclusive, em legislações específicas que regulam as relações entre mercado e sociedade civil, definindo papéis e garantias para as duas partes. Segundo Bauman:

Hoje, para muitas pessoas, as ações da cidadania se limitam à aquisição e à venda de bens (inclusive para os candidatos à própria vida pública), em vez de aumentar o alcance de sua liberdade e dos seus direitos a fim de ampliar os atos de uma verdadeira democracia. O consumidor é um inimigo do cidadão... Em todas as regiões "desenvolvidas" e ricas do planeta há numerosos exemplos de pessoas que voltam as costas para a política, numa apatia política e numa perda de interesse em relação aos processos políticos cada vez maiores. (BAUMAN apud PORCHEDDU, 2009, p. 681)

Tais mudanças ressignificam o espaço de lutas por direitos de cidadania, outrora respaldado pela política, no quadro de uma participação social mais ampla. Neste sentido, a desvalorização da participação na esfera pública, como suporte para a construção das identidades coletivas, enfraquece vínculos sociais e individualiza demandas por direitos. Mesmo que esse quadro não possa ser generalizado, pois grupos sociais organizados mantêm-se politicamente atuantes, a negação da política como elemento catalisador das demandas coletivas acaba cedendo terreno para a restrição de direitos, sobretudo sociais, sempre tão dependentes da ação do Estado e de suas intencionalidades.

No que concerne ao percurso da cidadania no Brasil, destaca-se o papel dos quase 400 anos de escravidão no transcurso da formação da sociedade nacional, deixando marcas indeléveis até os dias atuais. Precedido por esse ambiente, de constituição de direitos excludentes, o Brasil república se edificou reproduzindo a lógica calcada em uma sociabilidade desigual, seja em termos do acesso à participação política, seja no que concerne a disparidades de raça, gênero e renda, processo esse amplamente legitimado por grupos sociais distintos.

No Brasil, diferentemente dos países do centro capitalista, primeiro foram implantados os direitos sociais, em um ambiente ditatorial (década de 1930), para que somente depois surgissem os direitos políticos e civis, sempre em risco devido às possibilidades de ruptura democrática. Nas décadas seguintes, e, sobretudo, durante a Ditadura Militar (1964 - 1985), a expansão dos direitos sociais foi quase sempre utilizada como atenuante à restrição dos direitos políticos e civis, esses dois últimos reprimidos em nome da manutenção da ordem social e do progresso material (CARVALHO, 2008). 
Considerando o percurso histórico do país no século XX, é possível identificar avanços e retrocessos no acesso à cidadania, com efeitos significativos para a educação, no que concerne às oportunidades de acesso aos bancos escolares, mas também, em termos qualitativos, no que tange às discussões sobre currículo e metodologias de ensino e às desigualdades entre ensino público e privado. A seguir, são discutidos os condicionantes que se estabelecem na relação entre educação e cidadania, enfatizando a contribuição do pensamento educacional brasileiro.

\section{EDUCAÇÃO E CIDADANIA NO BRASIL}

Refletir sobre as relações entre educação e cidadania tem sido pauta de setores da intelectualidade brasileira nas últimas décadas, especialmente a partir do processo de redemocratização nos anos 1980. Permeado pelas aspirações democráticas depois de duas décadas de ditadura militar, o contexto da década de 1980 sinalizou para a reconstrução de direitos civis, políticos e sociais em que a relação entre o Estado e a sociedade civil deveria ser reformada em bases participativas e solidárias nos marcos da democracia representativa.

Movimentos públicos significativos mobilizaram a sociedade brasileira, notadamente o que ficou conhecido como Diretas Já!, marco da disputa pelo espaço público e fomentador de princípios participativos e democráticos no seio das massas urbanas. Se o voto direto para a presidência da república foi conquistado apenas em 1989, o movimento plural pelo sufrágio universal marcava uma intencionalidade política de disputa do Estado desde 1984.

Nesse contexto, a nova carta constitucional de 1988 canalizou o sentimento de mudança que o processo de abertura política, desde o final dos anos 1970, ensejava. Na esfera legal, a nova constituição da república afirmava direitos sociais e abria a possibilidade de uma nova fase na relação Estado-Sociedade no Brasil.

Um dos principais direitos sociais em pauta era o acesso à educação formal, portanto, o sistema escolar apresentava-se como o espaço por excelência da construção de sujeitos comprometidos com o ambiente democrático que se recolocava na agenda nacional. Assim, escolarização e democracia passariam a constituir a relação fundamental que assentaria a nova organização do país. E o desdobramento principal desta relação fundante foi a afirmação da cidadania.

Contudo, conforme está sendo discutido, a noção de cidadania apresentase problemática, e na sua relação com o sistema educacional verifica-se um 
movimento pendular entre lógicas de mercado e emancipatórias. Nesse sentido, Zitkoski (2006) discute as diferentes concepções de cidadania, apresentando as perspectivas clássica (grega), liberal, social-democrata, neoliberal e emancipatória. Em todas essas concepções a cidadania apresenta-se a partir da relação contratualista, na qual o Estado e a sociedade civil estabelecem fluxos de manutenção da ordem política.

No Brasil dos anos 1990, a promulgação da nova legislação educacional, a partir do contexto constitucional de 1988, demarca uma disputa importante daquele momento histórico: de um lado, a tentativa de aplicação do fundo público exclusivamente na educação pública estatal, de outro, o entendimento de que a diversificação dos arranjos escolares em todos os níveis seria mais adequada ao cenário econômico da época. De certa forma, as teses de diversificação das instituições escolares e a coexistência da oferta escolar pública e privada foram preponderantes no próprio texto da Lei de Diretrizes de Bases da Educação Nacional (BRASIL, 1996).

Assim, a noção de cidadania atrelada ao mercado encontrou acolhida no cenário que se desenhava nos anos 1990, principalmente a partir das medidas de reforma do aparelho estatal empreendidas no governo de Fernando Henrique Cardoso, do Partido da Social Democracia Brasileira (PSDB). Verifica-se a penetração de capital financeiro especulativo no setor da educação, principalmente nas instituições de ensino superior que passam a comercializar ações na bolsa de valores (OLIVEIRA, 2009).

Dessa forma, a democratização esperada ocorre nos marcos jurídicos que pressupõem que "todos são iguais perante a Lei", mas não aparece na distribuição das riquezas geradas, criando cenário de retomada de direitos políticos (podemos votar e ser votados no Estado democrático de direito) sem justiça social. Por um lado, mesmo com a garantia legal de participação política, não se constitui uma cultura política associativa em que a esfera pública seja, de fato, assumida pela população (DEMO, 2001). Por outro lado, esse descompasso entre o legal/procedimental e as práticas cidadãs é sentido no âmbito dos sistemas escolares, no qual a escola pública, histórica bandeira dos movimentos populares, convive com contradições de toda a ordem.

Com base na formação de espaços democráticos é que podemos pensar em cidadania, não em sua dimensão formal-jurídica de cunho liberal, na qual se confundem proprietário e cidadão, nem em sua dimensão social, na qual os direitos são concedidos pelo Estado em uma relação contratualista, na maior parte das vezes imposta acriticamente ao "cidadão passivo", mas em uma 
perspectiva de empoderamento dos sujeitos.

Por isso, ao revisitar concepções clássicas de cidadania e situar-se politicamente ao lado dos setores progressistas dos movimentos sociais, Marlene Ribeiro provoca a discussão no sentido de questionarmos se a cidadania seria o melhor caminho para a substantiva democratização da sociedade a partir de processos de justiça social. Pondera a autora que:

As dúvidas suscitadas pela observação dos rumos tomados por movimentos sociais populares e pela leitura de alguns autores clássicos da filosofia política me instigam a problematizar a bandeira quase consensual da "educação para a cidadania" como horizonte daqueles movimentos. Qual a possibilidade de alcance de uma cidadania concreta para índios, agricultores, desempregados, adultos analfabetos que justifique ser ela encarada como finalidade última da educação escolar para essas pessoas? Indo mais a fundo, pergunto: que limites a cidadania, enquanto uma categoria histórico-filosófica, apresenta em relação à sua aplicação às camadas populares, que são transpostas para a educação? E, se há limites, quais as potencialidades vivas de conquista de uma cidadania ativa, que ainda permitem afirmá-la como perspectiva da escolarização das camadas populares? Esse é um problema para os movimentos sociais populares, os quais precisam ter claras as suas reivindicações para, a partir delas, formular suas estratégias de luta. (RIBEIRO, 2002, p. 115-116)

Esse questionamento é válido e apresenta a pertinência do debate conceitual que busca-se desenvolver neste artigo. Ainda que de problemática adesão, a agenda dos setores progressistas sinaliza para a cidadania como uma estratégia de garantias individuais e coletivas diante de um sistema fundado na desigualdade social. A luta pela escola pública e gratuita em todos os níveis é histórica nos movimentos sociais que congregam trabalhadores(as), estudantes e camponeses(as). Dessa forma, “[...] no que tange à cidadania, parece haver um consenso de que a sua conquista implica o conhecimento de direitos e deveres por meio de uma sólida educação escolar básica” (RIBEIRO, 2002, p. 115).

A escola pública é vista como estratégica para um projeto mais inclusivo de país. Encontramos em Florestan Fernandes (1989) ações e reflexões sobre o papel estratégico da escolarização e a responsabilização do Estado por sua oferta, englobando acesso e permanência. Isso justifica que, entre as demandas sociais mais recorrentes da pauta de reivindicações dos setores populares, a escolarização tenha lugar assegurado.

Em virtude dessa pauta, no contexto de retomada do sufrágio universal, passamos a presenciar vitórias eleitorais de blocos partidários identificados com propostas de políticas públicas que enfrentassem as demandas sociais. 
Organizados nas denominadas Frentes Populares, partidos de esquerda e centro-esquerda assumiram a implementação de projetos em áreas estratégicas, como a educação/escolarização.

Um desdobramento dessas ações do bloco político hegemonizado pelo Partido dos Trabalhadores (PT) foi o projeto "escola cidadâ" (GADOTTI, 2006; AZEVEDO, 2005). Associado a outras práticas de reinvenção democrática e participação popular, como o Orçamento Participativo, esse projeto, em especial a sua construção no município de Porto Alegre, capital do Rio Grande do Sul, aponta para o entendimento de que:

[...] é um produto histórico da construção social das lutas pela afirmação democrática do direito à educação pública de qualidade. Educadores e educandos afirmaram seus princípios, refletiram suas práticas nas academias, nos sindicatos e nos diversos movimentos sociais. Foi a articulação de experiências democráticas, dos fazeres pedagógicos alternativos que fertilizaram o campo progressista em décadas de lutas que semearam e acalentaram o sonho embrionário de uma educação emancipadora, associada a um projeto sociocultural voltado à formação de sujeitos históricos capazes de, conscientemente, produzir e transformar sua existência. (AZEVEDO, 2005, p. 89)

Além da experiência de Porto Alegre nos anos 1990 e início dos anos 2000, outros municípios gaúchos administrados pela Frente Popular, como é o caso de Alvorada, também mobilizaram educadores(as) e a comunidade para (re)pensar a escola em uma perspectiva cidadã. Um dos assessores das experiências de escola cidadã e de organização de centros de educação de jovens e adultos, Carlos Rodrigues Brandão reflete sobre essa concepção de educação, sinalizando para o debate sobre educação popular, comunidade civil e sociedade política. Retomando princípios da escola cidadã, o autor destaca os eixos de gestão, currículo, avaliação e princípios de convivência (BRANDÃO, 2002), indo ao encontro do discutido por Azevedo (2005) que, além disso, destaca aspectos relacionados ao planejamento e orçamento participativo na escola, ao combate à violência escolar e ao uso da tecnologia a favor da instauração de novos processos de ensino-aprendizagem.

Esse projeto da escola cidadã reflete os anseios de democratização do sistema escolar, incluindo a possibilidade de revisão curricular, como foi o caso do sistema "ciclado" e não mais "seriado" implantado em Porto Alegre. De certa forma, é possível afirmar que a base pedagógica dialogou com o movimento de educação popular desencadeado no Brasil a partir dos anos 1960, encontrando 
em Paulo Freire uma importante referência.

Nas experiências citadas, certamente houve contradições entre o sistema formal de ensino como parte da burocracia estatal e as novas propostas participativas que incluíam, também, a própria comunidade para além dos(as) professores, funcionários(as) e estudantes. Contudo, inspirados na gestão de Freire no município de São Paulo no início dos anos 1990, o projeto ganhou corpo e se associou a princípios da chamada "educação crítica" (GANDIN, 2011) e, de forma mais ampla, ao que se denominou "cidade educadora", um movimento que busca envolver todo o território citadino com processos formativos (MORIGI, 2016).

Assim, ao falar de cidadania nos processos educativos nos associamos a perspectivas que buscam tornar a escola um lugar de socialização pautado pela democracia, pelo respeito à diferença e pela luta por uma sociedade mais justa. Não isento de contradições, os projetos de escola cidadã ou emancipatória produzem experiências que problematizam a cidadania pelo viés (neo)liberal que é marcado pelo individualismo e consumismo.

Entretanto, ao valorizar a cultura popular e buscar dar relevo a esses saberes nos currículos escolares, a concepção de escola cidadã convive com a sedução do "basismo", ou seja, a hipervalorização dos sujeitos populares em detrimento da necessária relativização desses saberes e de sua possível superação em termos científicos. Nesse sentido,

[...] reconhecer esses processos de constituição da cidadania e da identidade política onde eles estão não significa cair na visão ingênua do culto ao popular, nem passar do elitismo pedagógico ao populismo pedagógico, nem voltar a uma concepção épica da história, onde o antigo vilão, o povo, seja agora herói. (ARROYO, 2003, p. 77)

As considerações de Arroyo seguem a linha discutida por Paulo Freire em relação ao rigor que deve ser observado na construção de uma perspectiva crítica na formação de sujeitos a partir da educação problematizadora. Assim, construir processos escolares que sinalizem para a cidadania como uma expressão de um projeto democrático de sociedade torna-se tarefa presente em propostas curriculares emancipatórias.

Ao dizerem sua palavra, os sujeitos sociais potencializam sua ingerência em assuntos de natureza política. Essa construção demanda processos escolares provocadores do diálogo autêntico que é produzido na superação de cenários verticais entre pessoas e classes sociais. Para Freire (2005, p. 89), "não há palavra verdadeira que não seja práxis. Daí que dizer a palavra verdadeira seja 
transformar o mundo". Por isso, para a concepção freireana, reflexão e ação devem estar em relação dialética, por isso, quando há o sacrifício de uma dessas dimensões, podemos presenciar situações de "verbalismo" (sacrifício da ação) ou de "ativismo" (sacrifício da reflexão).

A construção da cidadania no ambiente escolar passa pela busca de uma formação crítica em que os conteúdos provenientes dos campos científico, filosófico e artístico não se sobreponham de forma artificial em relação ao cotidiano desafiador das pessoas. Considerando as contradições de financiamento dos sistemas educacionais que geram dificuldades de estrutura das escolas, de carreira para os(as) trabalhadores(as) e insuficiente quadro de formação continuada, a construção da cidadania passa exatamente pela assunção desses desafios e a busca de sua superação por meio do debate público e da organização política.

\section{CONSIDERAÇÕES FINAIS}

No Brasil contemporâneo, a construção da cidadania, por meio do acesso à educação, tem suscitado questões que remetem à relação entre acesso, qualidade e legitimação do direito à educação, visto que é no bojo do processo educativo que ocorre um movimento recíproco: acesso e qualidade da educação são aspectos condicionados pelo reconhecimento da legitimidade do direito à educação, do mesmo modo que a construção da legitimidade do direito à educação é dependente da capacidade das sociedades em garantir acesso e qualidade nos processos formativos. Desse modo, tornam-se indissociáveis o direito à educação, a legitimação desse direito e a cidadania, porque estão inseridos em um mesmo movimento, que é o de ampliar os horizontes do entendimento humano sobre o mundo.

Cabe destacar que, no quadro dos direitos de cidadania, o direito à educação é um valor recente na história da humanidade e, portanto, precisa ser reafirmado nas circunstâncias mais diversas, seja nos períodos de maior prosperidade ou mesmo durante crises econômicas. Partindo do argumento de Bobbio (2004), que sustenta a tese de que os direitos são historicamente relativos, então, a defesa da legitimidade social do direito à educação torna-se ainda mais relevante, visto que retrocessos no que tange à educação não são raros.

Ademais, a participação política é aspecto decisivo para a afirmação permanente do direito à educação, nas arenas políticas mais amplas, mas 
também no interior das instituições de ensino. Neste sentido, a escola e a universidade são espaços privilegiados para o debate sobre democracia, alteridade e justiça social, temas essencialmente políticos e que remetem a uma das principais finalidades da educação, que é a de romper com visões de mundo naturalizadas.

Neste cenário, a escola pública assume um papel de destaque, visto que se trata do espaço formativo da maioria, sobretudo das classes populares. Concordando com Arroyo (2003), considera-se que a construção da cidadania no ambiente da escola pública precisa relativizar saberes e práticas cristalizadas no senso comum, propondo outras formas de compreensão da realidade, sobretudo de natureza científica, sem desvalorizar a cultura popular, que é produto e produtora de identidades coletivas. Todavia, é fundamental superar a concepção instrucionista de educação, calcada na reprodução de conteúdos, que ao fim e a cabo contribui para a reprodução da própria estrutura desigual da sociedade.

\section{REFERÊNCIAS}

ARROYO, M. Educação e exclusão da cidadania. In: BUFFA, E.; ARROYO, M.; NOSELLA, P. (Org.). Educação e cidadania: quem educa o cidadão? 11. ed. São Paulo: Cortez, 2003. p. 31-80.

AZEVEDO, J. C. Escola cidadã: desafios, diálogos e travessias. 2. ed. Petrópolis, RJ: Vozes, 2005.

BAUMAN, Z. Modernidade líquida. Rio de Janeiro: Jorge Zahar Editor, 2001.

BOBBIO, N. A era dos direitos. Rio de Janeiro: Campus, 2004.

BRANDÃO, C. R. Soletrar a letra P: povo, popular, partido e política - a educação de vocação popular e o poder de Estado. In: FÁVERO, O.; SEMERARO, G. (Org.). Democracia e construção do público no pensamento educacional brasileiro. Petrópolis, RJ: Vozes, 2002. p. 105-145.

BRASIL. Lei de Diretrizes e Bases da Educação Nacional. Brasília, 1996. Disponível em: $<$ http://portal.mec.gov.br/seesp/arquivos/pdf/lei9394_ldbn1.pdf >. Acesso em: 28 mai 2016.

CARVAlHO, J. M. Cidadania no Brasil: o longo caminho. Rio de Janeiro: 
Civilização Brasileira, 2008.

CERQUIER-MANZINI, M. O que é cidadania. São Paulo: Brasiliense, 2010.

DEMO, P. Cidadania pequena: fragilidades e desafios do associativismo no Brasil. Campinas, SP: Autores Associados, 2001.

FERNANDES, F. O desafio educacional. São Paulo: Cortez/Autores Associados, 1989.

FREIRE, P. Pedagogia do oprimido. 41. ed. São Paulo: Paz e Terra, 2005.

GADOTTI, M. Escola cidadã. 11. ed. São Paulo: Cortez, 2006.

GANDIN, L. A. Escola cidadã: implementação e recriação da educação crítica em Porto Alegre. In: APPLE, M.; AU, W.; GANDIN, L. A. (Org.). Educação crítica: análise internacional. Porto Alegre: Artmed, 2011. p. 380-383.

MORIGI, V. Cidades educadoras: possibilidades de novas políticas públicas para reinventar a democracia. Porto Alegre: Sulina, 2016.

OLIVEIRA, R. P. A transformação da educação em mercadoria no Brasil. Educação \& Sociedade, Campinas, v. 30, n. 108, p. 739-760, out. 2009.

PORCHEDDU, A. Zygmunt Bauman: entrevista sobre a educação. Desafios pedagógicos e modernidade líquida. Cadernos de Pesquisa, São Paulo, v. 39, n. 137, p. 661-684, ago. 2009. Disponível em: <http://www.scielo.br/scielo.php? script=sci_arttext\&pid=S0100-15742009000200016\&lng=en\&nrm=iso $>$. Acesso em: 20 mai 2016.

RIBEIRO, M. Educação para a cidadania: questão colocada pelos movimentos sociais. Educação e Pesquisa, São Paulo, v.28, n.2, p. 113-128, jul./dez. 2002.

ZITKOSKI, J. J. Educação e emancipação social: um olhar a partir da cidade educadora. Espaço Pedagógico, Passo Fundo, v. 13, p. 09-18, 2006. 


\section{Educación y ciudadanía: reflexiones sobre un debate contemporáneo}

Resumen: En este artículo se aborda el panorama del derecho a la educación en el Brasil contemporáneo, movilizando conceptos de la teoría social para discutir las interconexiones entre la ciudadanía y la educación, así como las contribuciones de los estudiosos brasileños del tema. Inicialmente, cabe destacar que la experiencia histórica de Brasil, en relación a los derechos sociales, difiere sustancialmente de lo que sucedió en los países de centro capitalista, ya que éstos últimos vivieron la experiencia del Welfare State. Por otro lado, en términos conceptuales, los derechos necesitan ser entendidos como históricamente relativos, ya que lo que se legitimado socialmente como relevante para una sociedad específica o en un período histórico específico, puede no ser considerado en otros. Considerando el camino histórico de Brasil en el siglo XX, es posible identificar avances y retrocesos en el acceso a la ciudadanía, con efectos significativos para la educación. En el Brasil contemporáneo, la construcción de la ciudadanía, a través del acceso a la educación, ha planteado cuestiones que se refieren a la relación entre acceso, calidad y legitimación del derecho a la educación, visto que es en el centro del proceso educativo que ocurre un importante movimiento recíproco: el acceso y la calidad de la educación son aspectos condicionados por el reconocimiento de la legitimidad del derecho a la educación es dependiente de la capacidad de las sociedades en garantizar el acceso y la calidad de los procesos formativos. De ese modo, se convierten en inseparables el derecho a la educación, la legitimación de este derecho y la ciudadanía, inseridos en el movimiento de amplitud de los horizontes de la comprensión humana del mundo.

Palabras-clave: Educación para la ciudadanía. Derechos sociales. Educación en Brasil. 


\title{
Education and citizenship: Reflections on a contemporary debate
}

\begin{abstract}
This article concerns the panorama of right to education in contemporary Brazil, drawing on concepts from social theory to discuss the interconnections between citizenship and education, as well as the contributions from Brazilian scholars on the theme. First, one must point out that the Brazilian historical experience as regards social rights differs significantly from what took place in countries of the capitalist center, which were subject to the experience of the welfare state. On the other hand, in conceptual terms, rights must be understood as historically relatives, since what is socially legitimated as relevant in a specific society, or in a given historical period, may be disregarded in another. Concerning Brazil's history in the $20^{\text {th }}$ century, it is possible to identify advances and hindrances in access to citizenship, with significant results for education. In contemporary Brazil, construction of citizenship through access to education has been raising questions about the relation between access, quality, and legitimation of the right to education, since it is in the midst of the educational process that an important reciprocal movement takes place: access and quality of education are conditioned by the recognition of the legitimacy of the right to education, while at the same time this legitimacy is dependent upon the capacity of societies in warranting access and quality in formative processes. Thus, the right to education, the legitimation of this right and citizenship become intertwined, and are a part of the expanding movement of human understanding in relation to the world.
\end{abstract}

Keywords: Education for citizenship. Social rights. Education in Brazil. 
Educação e cidadania: reflexões sobre um debate contemporâneo 